\title{
What New Orleans' Vulnerability Taught Us About Public Health Preparedness: Vulnerability Has a Face and a Name
}

\author{
Evangeline Franklin, MD, MPH; Kevin U. Stephens Sr, MD, JD
}

$\mathrm{H}$ urricane Katrina burned indelible images in the memories of Americans who, during the summer and fall of 2005, watched their fellow citizens endure suffering that we previously associated with the so-called developing world. Later, we learned of people who had died in or near their homes, in their beds, or in their wheelchairs because they could not evacuate. Observers wondered how such things could happen in the United States.

Katrina affected the entire population in New Orleans, and the voluntary evacuation that occurred because of this storm was the most successful in the city's history. Yet for various reasons, thousands of people were left behind. Some chose not to abandon beloved pets, some lacked the money to put gas in their car or to get themselves to a bus or train, some had no idea how to function in a different location, and some simply had no place to go and no friend or relative with whom to stay. But there was a deeper issue, familiar to public agencies and advocacy groups - the community had a sizeable population of citizens already burdened by poverty and high levels of disability. These residents required significant daily assistance from others under normal circumstances.

The National Incident Management System tasks public health officers with coordinating the medical and public health components of all-hazards planning, response, and mitigation, and the public health profession, by dint of its history, ethics, and professional standards, is committed to ensuring that all citizens, in particular those with the greatest disabilities and fewest resources, benefit from such preparedness and response activities. But who, exactly, are "the vulnerable"? Media coverage of Hurricane Katrina put a human face on this somewhat vague term because it highlighted individuals waiting to be rescued, enduring unsafe, unsanitary, and overcrowded conditions, and confronting the appearance that they had been overlooked or abandoned.

Even well-intentioned public health professionals occasionally perceive or describe vulnerable, impoverished, and disabled populations as a faceless, nameless mass. Such a perception is both inaccurate and a severe impediment to a disaster response that effectively serves these populations. To overcome this inadequacy, a deeper understanding of vulnerability is required. Citizens who are disabled, permanently or temporarily, or who live hand to mouth, face many challenges due to their dependence upon others - the aide who takes them for walks, the paratransit bus driver who helps them on and off the vehicle, the home health nurse, the social worker, and even the trained assistance animal. Publicly provided services are often the only resources these people have; they often depend entirely upon those services for their survival and daily functioning.

Fortunately, in most American communities there are government agencies, civic associations, and faith-based groups that interact on a regular basis with those to whom we refer as "vulnerable populations," and who know those people as individuals with families, friends, and extra needs. Furthermore, some citizens with specific limitations have registered with an advocacy group, or have a TTY connection in their home. Many elderly adults, in spite of significant mobility issues, may attend daily activities at senior centers. Some may use paratransit. Sometimes faith-based organizations reach out to parishioners who have become compromised because of age, injury, or illness. Even homeless people have resources and in many cities providers search for and reach out to them daily.

In other words, we really do know the name, address, and telephone number of many of the individuals, families and households who comprise the "vulnerable populations." In a growing number of localities, we can also know them from voluntary special needs registries such as the New Orleans Vulnerable Populations Registry, established in reaction to Hurricane Katrina. Such registries enable citizens to self-identify their need for help with transportation, pet care, health, communications and other needs during an evacuation or other emergency response.

It is clear that planning for these unusual circumstances is a significant challenge and one that emergency planners and public health officers must address critically and strategically. Location-based hazards analysis plays a big part in determining the general road map, but so does matching up the proper resources with the needs of the population. To make a reasonable set of customized plans that can be executed, officials must build and sustain collaborative relationships with organizations that serve vulnerable citizens as part of their routine operations.

Even taking community-level resources into account, however, there is a subset of the population that is extremely difficult to find - people who are housebound disabled and people 
who are confined to bed - whose frailty and ailments make them severely compromised by the effort of evacuation. Many have limited or impaired cognitive skills and cannot understand invitations to enroll in a registry, check in with a neighbor, or seek help during an emergency. Some live at a subsistence level, do not have access to transportation, and have no support system. Many are invisible to the "outside world" and during a disaster confront the alternatives of a door-to-door rescue or collection as a fatality. These citizens need community advocates, neighbors who are encouraged to reach out and help create a connection to the voluntary registry, so that a process of evaluating and matching needs and resources can be initiated.

Traditional and nontraditional social services providers try hard to resolve the health and social disparities of these vulnerable citizens. They played an essential role and provided critical resources in the response and recovery for many of New Orleans's most vulnerable people, but they are not a complete solution.

Systemic societal issues contribute to the loss of independence that hampers the execution of rescue and response when disaster strikes. We all know that a litany of factorsinadequate prenatal care, poor nutrition at home and school, gun and drug violence, unequal access to health and medical care, or the lack of regular exercise, to name just a fewcontribute to a loss of independence in children and adults. Despite this awareness, it sometimes seems that in America's approach to disaster preparedness, we are condemned to reacting when we could instead transition a large number of citizens to healthy independence. The social determinants of health are fundamental principles for the success of citizens in a safe and healthy community. These are principles that should be mastered for a proper response and recovery. How many more prob- lems might we solve and how many more people could aspire to the pursuit of happiness (even during a disaster) if we adequately resolved the social determinants of the health inequality that plagues American society?

One of Katrina's most compelling lessons arose from the experiences of the New Orleans diaspora, which included many people of limited means, who arrived with few assets and who lost much in the storm. These people, in general, landed in communities committed to help (or, at a minimum, not impede) their fellow citizens' flight for survival, even in the face of those communities' struggle to service their own needy and vulnerable populations. Strained resources were shared to supply a large number of displaced New Orleans citizens on extremely short notice and with virtually no preplanning. The experiences of the new arrivals and their host communities demonstrate that humankind must learn not only to work together but also to have a greater and more equitable distribution of critical resources such as food, water, education, economic stability, and health services when disasters occur. Effective emergency preparedness requires the community to be invested in all of its parts and all of its citizens, daily and incrementally, and not simply in a crisis.

Authors' Affiliations: Dr Franklin is the former Director of Emergency Preparedness, New Orleans Health Department, and is an adjunct professor of homeland security studies at the Tulane University School of Continuing Studies; Dr Stephens is the former director of the New Orleans Health Department.

Correspondence: Address correspondence and reprint requests to Dr Evangeline Franklin, City of New Orleans Health Department, 1300 Perdido Street, New Orleans, LA 70122 (e-mail: erfranklin@cityofno.com).

Received for publication: Received for publication August 9, 2010; accepted August 10, 2010.

Authors' Disclosures: The authors report no conflicts of interest. 